\title{
Light REE inclination and distance from volcanic front; a case of volcanic rocks in Northeastern Japan
}

\author{
Tatsuya Fujtani ${ }^{1}$ and Akimasa Masuda ${ }^{2}$ \\ Department of Earth Sciences, Kobe University, Nada, Kobe 657, Japan
}

(Received March 9, 1981: Accepted July 13, 1981)

\begin{abstract}
Rear-earth abundances were determined precisely for twenty-four volcanoes of the Northeastern Japan Islands. The inclination of the pattern for lighter REE span was found to depend sensitively on the distance of the volcano from the volcanic front. The $\mathrm{f}_{\mathrm{w}}$ value (residual liquid fraction) for the volcano situated near the volcanic front is about unity and decreases rapidly with the distance from the volcanic front. The rate of change of $f_{w}$ is almost parallel with the rate of change in the volume of volcanic products with the distance from the volcanic front. Also it is emphatically noted that the relatively chondritic REE pattern not only actually emerges as a rather special case at the front but can be significant in consideration of possibly incipient magma. Moreover, it is suggested that there can be two kinds of sources of genetically different natures for apparently chondritic, initial melts.
\end{abstract}

\section{INTRODUCTION}

Nowadays it is recognized that mid-ocean ridges and continental margins are geologically most active regions in the world. According to the theory of sea-floor spreading, oceanic plates are subducting along continental margins and island arcs are formed there in many cases. Japan Islands are situated along the boundary between the Pacific Ocean plate and the Eurasia plate (LE PICHON, 1968) and are formed as typical island arc systems (SugImura and UyedA, 1973). Petrological investigations of the island arcs have been carried out in connection with their geotectonic settings.

For Japan Islands, the zonal distribution of petrological characteristics of volcanoes in the direction normal to the island arc has been recognized (ToM 1961). Sugimura (1960) devised the $\theta$ value for the volcanoes as an index characteristic of major elements of parental magma and by using that value, he made it clear that there was a serial change in the property of basaltic magma across the arc. These zonal distributions were considered to be closely connected with the geotectonic position which could be represented simply by the distance of the volcano from across the volcanic front (Sugrmura, 1968).

Studies of trace element geochemistry for island arc volcanism have been proceeding vigorously (e.g., TAYLOR and WHITE, 1965; HARTHERTON and DiCKINSON, 1969; JAKES and WHITE, 1969; HAWKESWORTH et al., 1977). Investigations on rare-earth elements (REE) of volcanic rocks in Japan were commenced by MASUDA (1966). After that, other researchers have grappled with the same problem (PHILPOTTS et al., 1971; YAJMA et al., 1972; MASUdA, Y. et al., 1976). FuJimaKi and Kurasaẃa (1980) observed that light rare-earth elements in the Quaternary basaltic rocks in Japan increase from the Pacific Ocean side toward the Japan Sea side in a broad sense.

We have precisely determined the rare-earth elements in the Quaternary volcanic rocks in the Northeastern Japan Islands. We will try to examine the relationship between the characters

Present addresses: Marine Technical College, Nishikura-cho, Ashiya $659,{ }^{1}$ and Department of Chemistry, University of Tokyo, Hongo, Tokyo $113,{ }^{2}$ Japan. 
of REE geochemistry of these volcanoes and their geotectonic settings and throw a new light on island arc volcanism.

\section{Samples AND ANALYSIS}

Northeastern part of Japan Islands is composed of the east end of the Kurile Arc and the main part of the Northeast Japan Arc. (Hokkaido Island and the north part of Honshu Island cover this area.) And these two arcs join at south Hokkaido. We have determined the rareearth elements and partly $\mathrm{Ba}$ in the sixteen rocks from the Quaternary volcanoes of the Northeast Japan Arc and the eight rocks from the Quaternary volcanoes of the Kurile Arc (Fig. 1).

In this study we analyzed usually just one sample for each volcano. It might be said that the samples studied were rather randomly sampled, but it is believed that our samples are not special rocks for the volcanoes concerned but are adequately close to the representative rocks for those volcanoes. $\mathrm{SiO}_{2}$ content ranges from 53 to $68 \%$ for the rocks analyzed for REE, and most of them are andesite.

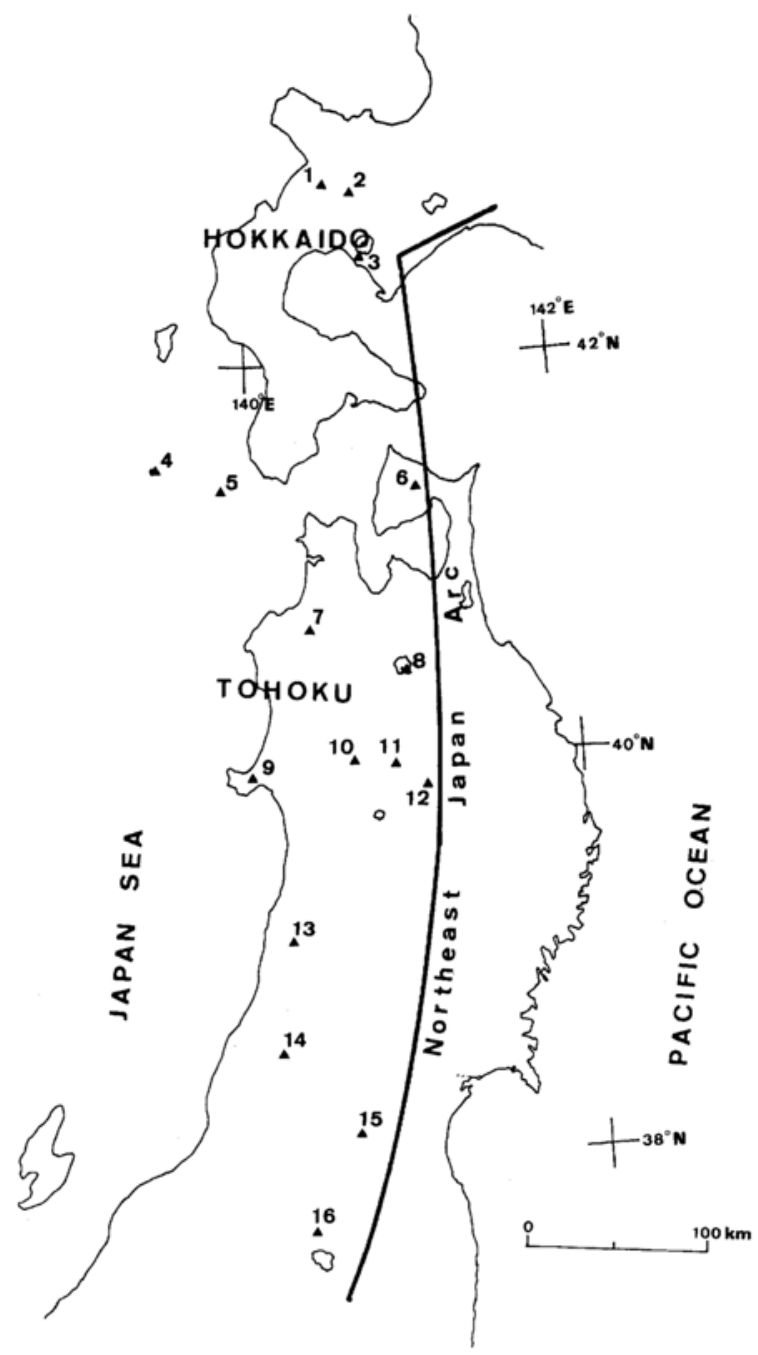

Fig. 1a. Locations of the Quaternary, Northeast Japan Arc volcanoes investigated for REE patterns; numeral symbols for volcanoes correspond to those in Table 1 and bold solid line indicates the Quaternary volcanic front. 


\section{RESUlTS AND Discussion}

\section{REE pattern analysis}

The analytical results for the abundances of REE and $\mathrm{Ba}$ are given in Table 1, and Figs. 2, 3 and 4. The REE and $\mathrm{Ba}$ abundances in the leedey chondrite (MASUDA et al., 1973) are employed as normalizing values. All of the REE patterns obtained in this study, except two, posses a common feature that the lighter REE are enriched and show an inclined line and the heavier REE afford almost a flat line. But the fine structure of REE patterns slightly varies from volcano to volcano. By the location of the volcanoes and the features of the REE patterns, Northeastern Japan Islands can be divided into following three areas: (I) Tohoku and South Hokkaido area, (II) Central Hokkaido area, and (III) East Hokkaido area (cf. Table 1 and Fig. 1).

(I) Tohoku and South Hokkaido area

Figure 2 shows representative REE patterns of the Quaternary volcanic rocks in the Tohoku and South Hokkaido area. Their patterns exhibit the features characteristic of one of the typical liquid-type REE patterns (MASUDA, 1966). The patterns are composed of two rectilinear segments and the two lines intersect at a position of middle REE. As a peculiar unique case, the pattern of Osore-zan basaltic andesite is relatively chondritic, that is, an almost perfectly flat pattern. Though some terrestrial materials which have relatively chondritic REE patterns have been reported so far (e.g., JAKES and GILl, 1970; Schilling, 1971; SHIMOKAWA and Masuda, 1972; KaY and HubBard, 1978), there are very few examples that indicate almost perfectly flat patterns. In addition to such a unique feature, the heavy REE span (Gd-Lu) of the pattern for Osore-zan basaltic andesite indicates a slightly concave curve, not a perfectly straight line, and the normalized value of $\mathrm{Er}$ is the lowest of all the heavy REE. This feature is seen not only for Osore-zan volcano but for most of the Quaternary volcanic rocks in this

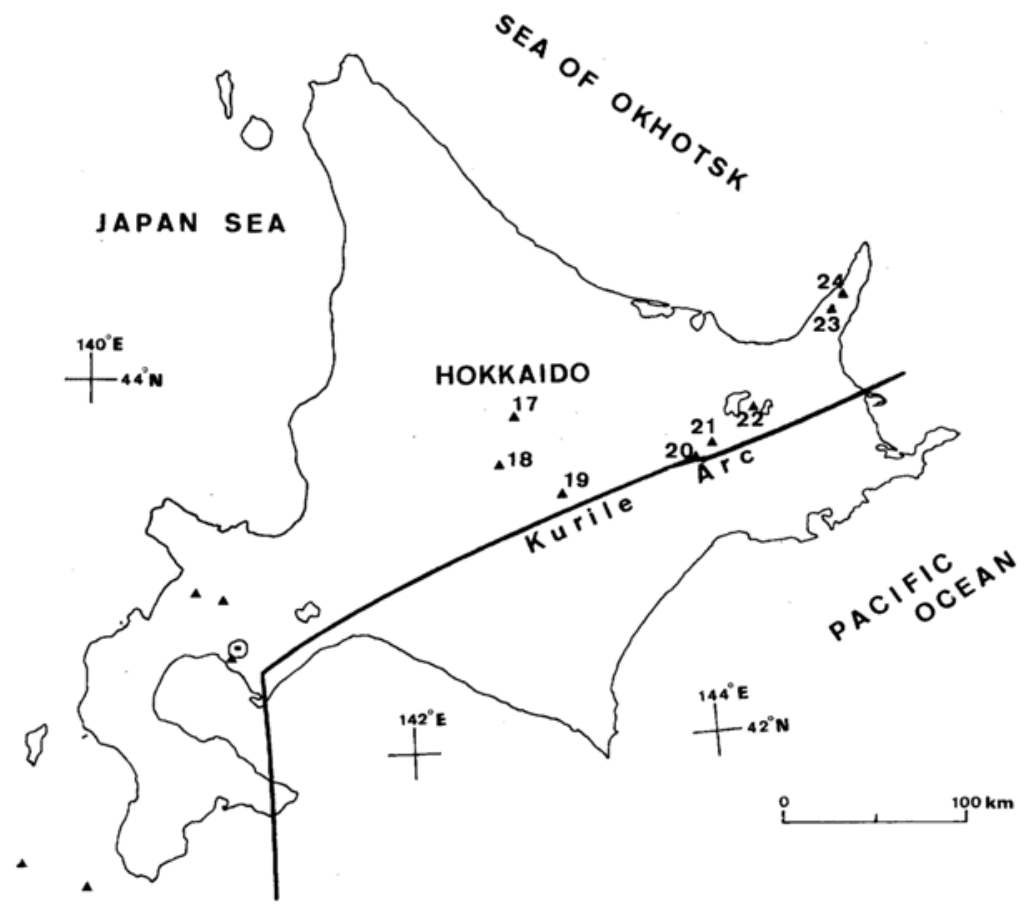

Fig. 1b. Locations of the Quaternary, Kurile Arc volcanoes investigated for REE patterns (cf. Fig. 1a). 


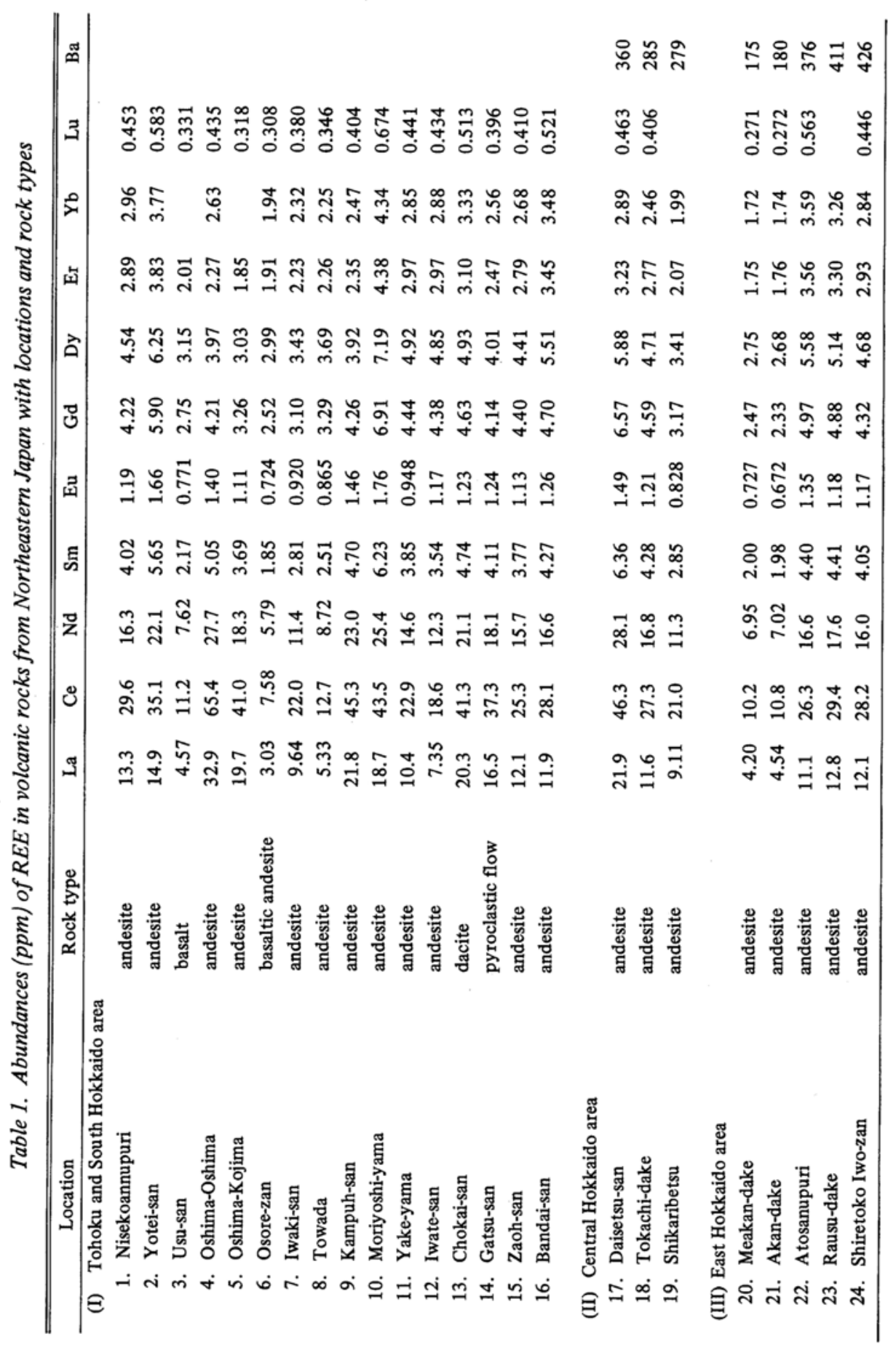


area in a greater or less degree. It might be noted that a similar characteristic feature was recognized for the REE in Antarctic meteorites (SHIMIZU et al., 1979).

The REE patterns of other volcanic rocks in the Tohoku and South Hokkaido area can be discussed about two parts, i.e., the lighter REE span and the heavier one, as mentioned above. Generally, the heavier REE span shows an almost flat line and the level of the normalized values for the flat lines ranges from 8.0 to 16.0 . The REE patterns of the andesites for the volcanoes located near the Japan Sea side (e.g., Kampuh-san, Oshima-Oshima, and -Kojima) do not show exactly flat lines for the heavier REE span, but slightly positively inclined (rightward increasing) straight lines. Apart from this fine

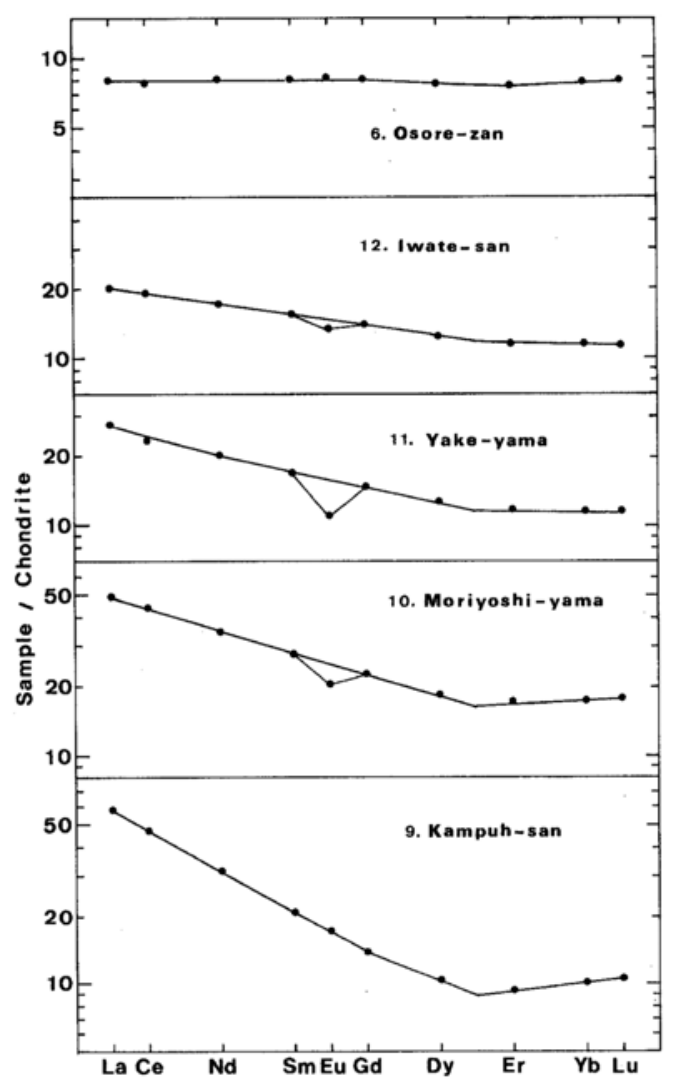

Fig. 2. Chondrite-normalized REE patterns of five out of sixteen volcanic rocks from the Tohoku and South Hokkaido area. Four volcanoes, except Osore-zan, are situated along a similar latitude, $40^{\circ} \mathrm{N}$, normal to the volcanic front. effect, which will be discussed elsewhere, the heavy REE patterns for this area, on the whole, show flat lines and their levels are relatively low.

The patterns of the volcanic rocks in this area show inclined straight lines for the lighter REE span and the normalized value for La has the maximum value of all of REE. The inclinations of the patterns for the lighter REE span vary from volcano to volcano. The REE pattern of the Oshima-Oshima andesite has the largest inclination of the lighter REE span and, as an extreme, the pattern of the Osore-zan basaltic andesite shows a flat line and naturally, its inclination of the lighter REE span is substantially zero. Corresponding inclinations for other volcanoes vary between values for Oshima-Oshima volcano and Osore-zan volcano, and moreover, this variation is seen to depend on the location of the volcano. That is, from the side of Pacific Ocean to the side of Japan Sea, the inclinations of the patterns for the lighter REE span increase gradually (see Fig. 2) in ways similar to the behavior of other incompatible elements (Kuno, 1966; Ui and Aramaki, 1978; SakuYaMA, 1979).

In addition to those features, two straight

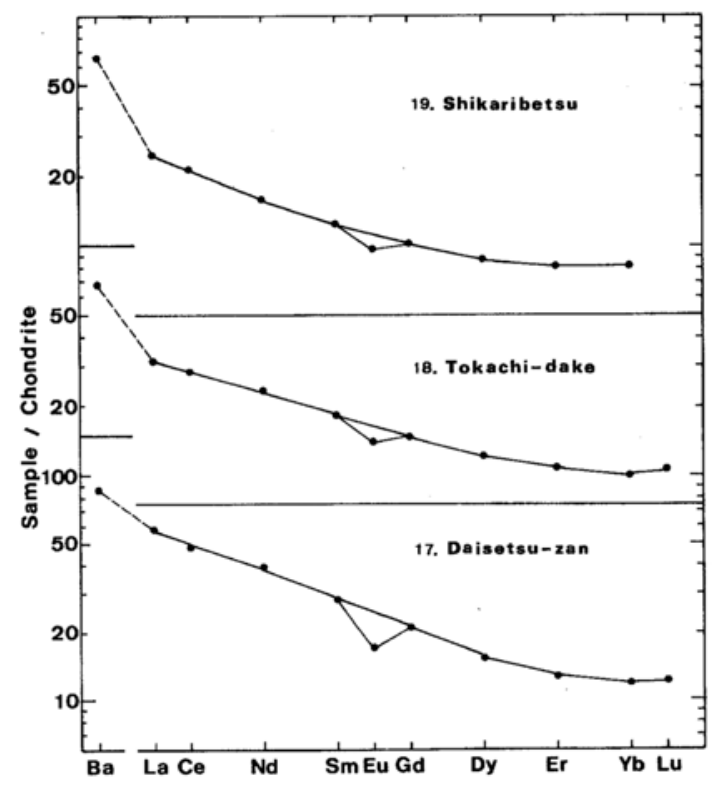

Fig. 3. Chondrite-normalized REE patterns and Ba of three volcanic rocks from the Central Hokkaido area. 
line segments of the REE pattern for the volcanic rocks in this area intersect at a position of an element; this inflectional point is situated at Ho in many cases (ten volcanoes in this area), and at $\mathrm{Tb}$ (four volcanoes) and Dy (one volcano).

\section{(II) Central Hokkaido area}

There are three volcanoes investigated for the Central Hokkaido area. Figure 3 shows the REE patterns of the three volcanic rocks in this area. Although the tendency that the lighter REE are leftward concentrated is similar to that in Tohoku and South Hokkaido area rocks, the shape of whole REE pattern is somewhat distinct from patterns of other areas. The REE patterns of the volcanic rocks of this area cannot

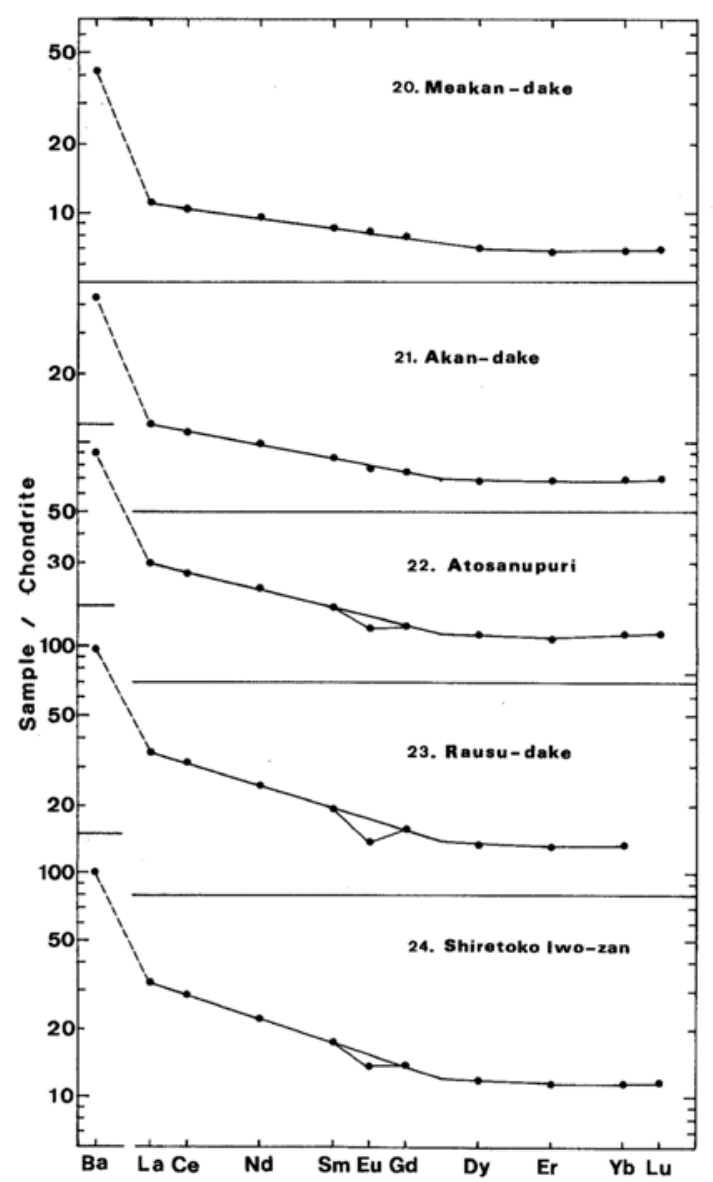

Fig. 4. Chondrite-normalized REE patterns and Ba of five volcanic rocks from the East Hokkaido area. be divided into two linear segments and the heavier REE span shows a slightly concave curve. Naturally, the inflectional points of patterns cannot be defined. Furthermore, a close inspection reveals that the linearity of the patterns for the lighter REE span is not so good as the patterns of other areas.

The normalized values of $\mathrm{Ba}$ are higher than those of $\mathrm{La}$ as those in other island arcs (PHILPOTTS et al. 1971).

\section{(III) East Hokkaido area}

There are five volcanoes studied in the East Hokkaido area. Figure 4 shows the REE patterns of their volcanic rocks. These five patterns appear quite simple and are similar to one another. The features of their patterns are similar to those of the Tohoku and South Hokkaido area mentioned above. The linearities of the lighter REE span are very high and the inflectional points are markedly clear. The differences among five patterns are degree of inclination of the lighter REE span and position of the inflectional point. The degree of inclination shows a little but recognizable difference in spite of geographic closeness of volcanoes. (Dependence of this difference on mutual distance between them will be observed later.) The inflectional point appears at $\mathrm{Tb}$ for four volcanoes and at Ho for the only one volcano, while the majority of volcanoes in Tohoku and South Hokkaido area show the inflection at Ho.

\section{Inclinations of REE patterns and distances from} the volcanic front

The common feature of all the REE patterns of the volcanic rocks investigated is that the lighter REE span shows an inclined straight line. But the inclination of that straight line varies from volcano to volcano and this variation seems to depend on the situation of volcano relative to the island arc in question. Here let us define the lighter REE span inclination $S$ as a rate of change of common logarithm of chondritenormalized value per increase of atomic number by unity, which is evaluated from the inclination of the rectilinear line. (A scrutiny reveals that the 
general linear trend for the lighter REE span has sometimes a slight break at a certain point such as $\mathrm{Nd}$ or $\mathrm{Sm}$. In such a case, the weighted mean for the values for sub-spans is used.) As mentioned above, the REE patterns for the Tohoku and South Hokkaido area have suggested a fact that the inclination of the lighter REE span changes with the variation of location of volcano from the Pacific Ocean side to the Japan Sea side. At this point, let us plot the inclination value $\mathrm{S}$ defined above against the distance of volcanoes from across the Quaternary volcanic front (cf. Fig. 1). All the data obtained are plotted in Fig. 5. Both solid circles and open squares refer to the volcanoes belonging to the Northeast Japan Arc and open triangles to those belonging to the Kurile Arc. (The Northeast Japan Arc is divided conveniently into two subareas, which correspond to the different symbols for volcanoes of this arc.) It is easily seen that for the Quaternary volcanoes studied, there is a close relation between the REE pattern inclination and the distance from the Quaternary volcanic front. It should be noted that none of other incompatible elements display a correla- tion higher than the dependence of REE inclination on the distance from the volcanic front. The line $\mathrm{A}$ is drawn by the least square method for the data of twelve volcanoes belonging to the north part of the Northeast Japan Arc (solid circles in Fig. 5). The line B is drawn by the same way for the data of the volcanoes in the south part of the Northeast Japan Arc; they (open squares in Fig. 5) involve Chokai-san and volcanoes farther south of it. By using the data of the volcanoes situated on the Kurile Arc (open triangles in Fig. 5), the line $\mathrm{C}$ is drawn, but in the calculation for this line, the Shikaribetsu volcano which fairly deviates from the trend is excluded.

The results obtained intrigue us in that the line A runs almost parallel with the line C. This means that the east end of Kurile Arc is very similar to the north part of Northeast Japan Arc regarding the variation of REE pattern, especially for the light REE span, when going from the side of the trench toward the side of the continental margin. On the other hand, the south part of Northeast Japan Arc seem to be different from its north part in the dependence of the

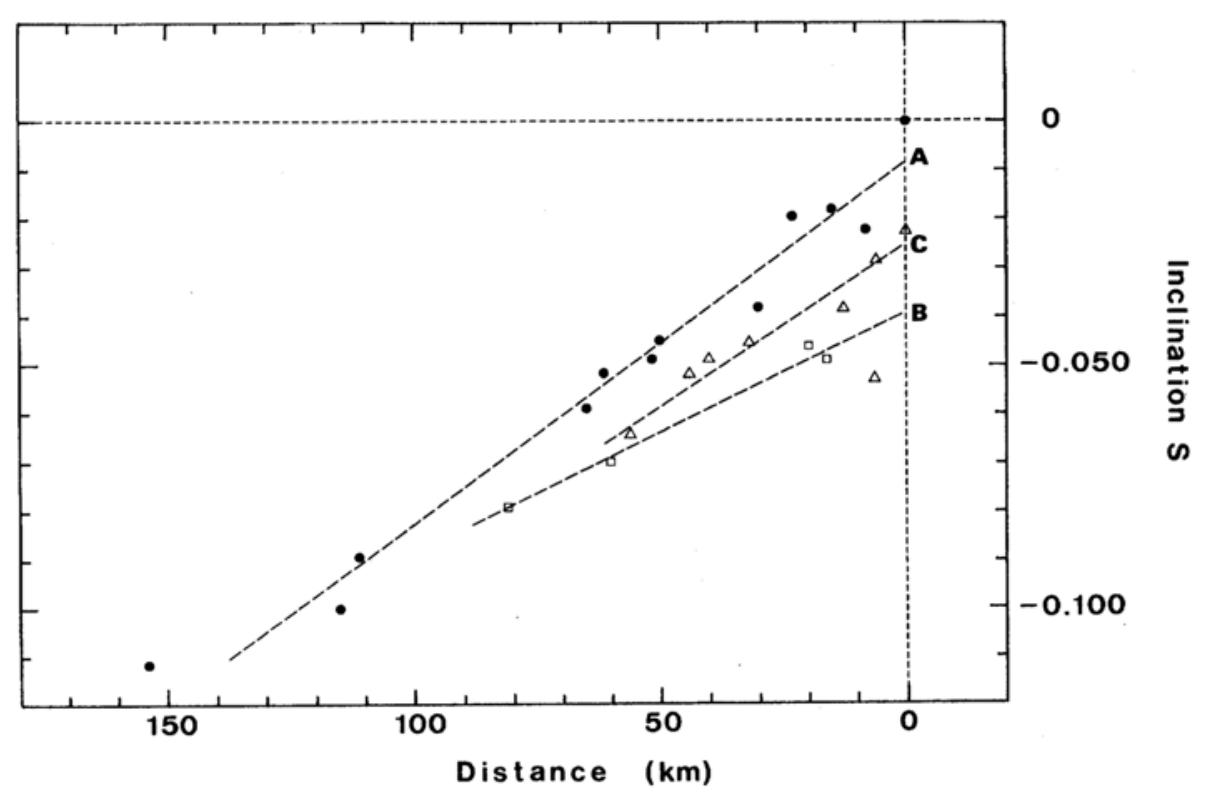

Fig. 5. Plot of light REE inclination $S$ (see text) against the distance of volcano from the Quaternary volcanic front; solid circles refer to the volcanoes of the north part of Northeast Japan Arc, open squares to the volcanoes of the south part of the same arc, and open triangles to the volcanoes of Kurile Arc. 
variations of REE pattern on the volcanic front distance. These facts are considered to give some suggestions concerning the similarity in the structure of the upper mantle for the region studied. It can be considered that the structure of the upper mantle under the east end of Kurile Arc is more analogous to that under the north part of Northeast Japan Arc than that under the south part of Northeast Japan Arc. However, it might be pointed out that the REE patterns for the volcanoes of Kurile Arc show in general inflectional points at Ho, while those of Northeast Japan Arc show inflectional points mostly at $\mathrm{Tb}$. This may reflect difference in some physicochemical conditions such as pressure.

Six of seven volcanoes situated on Kurile Arc show a fine correlation between inclination $S$ for the REE patterns of their rocks and the distance from the volcanic front, represented by line $\mathrm{C}$ in Fig. 5. It is emphasized that, even for the volcanoes which are situated less than $10 \mathrm{~km}$ distant from one another, difference in inclination $\mathrm{S}$ between them is in keeping with the general trend of correlation under consideration; a case of Akan volcano and Meakan volcano and another case of Rausu-dake volcano and Shiretoko-Iwo-zan volcano. As mentioned above, the REE patterns of three volcanic rocks from Central Hokkaido show a small irregularity compared with the patterns of other areas (see Fig.

3). Although Shikaribetsu volcano deviates from the line $\mathrm{C}$ in Fig. 5, the rest, Daisetsu-zan and Tokachi-dake volcanoes, are plotted indisputably on the line $\mathrm{C}$ in Fig. 5.

\section{$f_{w}$ value obtained from inclination $S$}

All of the REE patterns presented thus far are classified as liquid-type after MASUDA (1966). The majority of them is a typical liquidtype REE pattern with high linearity for light REE pattern and an inflectional point at a certain middle REE (MASUdA, 1979a). These patterns, especially, the light REE parts of them, vary systematically depending on the relative situation of the volcano to the volcanic front. According to Masuda's postulate, the genesis of the rocks with liquid-type REE patterns aforementioned can be interpreted by following assumption. First, there is a primary melt with relatively chondritic REE abundances. And the fractional solidification starting from such a melt proceeds under operation of the bulk partition coefficients of REE which show rectilinear function corresponding to "terrace-shaped" one (TANAKa and Nishizawa, 1975; Masuda et al., 1977; ShImizu, 1980). In the course of solidification, concentration of a certain element in the liquid phase varies according to the following equation:

$$
\log \left(C_{L} / C_{O}\right)=(k-1) \log f_{w}
$$

where $f_{w}=$ ratio of mass of residual liquid relative to the initial liquid mass $\left(f_{w}\right.$ is designated as residual liquid fraction value), $\mathrm{k}=$ bulk partition coefficient of a given element, $C_{L}=$ its concentration in the residual liquid, and $\mathrm{C}_{\mathrm{O}}=$ concentration of the same element in the "initial" melt hypotethically with chondritic REE abundance ratios. Then we can easily evaluate $C_{L} / C_{O}$ for assumed values of bulk partition coefficient $\mathrm{k}$ and residual liquid fraction value $f_{w}$. One of the examples for the variation of typical liquid-type REE patterns under operation of terrace-shaped partition function was shown in Fig. 3 in Masuda (1979a), where the degree of the inclination of the pattern for the lighter REE span increases with $f_{w}$ value and the patterns for heavier REE span remain flat. The variation of the REE patterns of the Quaternary volcanic rocks in the Tohoku and Hokkaido area can be dealt with as a case concordant with such an effect.

Here let us apply the assumption given above to the explication of the REE patterns obtained in this study. We posit that starting melt was relatively chondritic with respect to $\mathrm{REE}$ and that the REE patterns of the volcanic rocks in question correspond to the liquid phases for the various steps of $f_{w}$ value in the course of fractional solidification. In general, the $f_{w}$ value for the liquid-type REE pattern can be derived from the inclination $S$ of the pattern, if a set of rectilinear REE partition coefficients is employed. 
Mathematically speaking, in order to obtain the $f_{w}$ value only, we have only to know a difference (D) in partition coefficient between the adjacent lanthanides for the inclined part instead of the set of partition coefficient. That is, Eq. (1) is equivalent to:

$$
\log f_{w}=\frac{S}{D}
$$

Here employing the set of "terrace-shaped" REE bulk partition coefficients estimated by MASUDA (1979b) with some modification for the inflectional point, we can evaluate the $f_{w}$ values for the REE patterns of the volcanic rocks under consideration. Naturally, the $f_{w}$ value for the Osore-zan basaltic andesite becomes unity, because its pattern is horizontal, i.e., $\mathrm{S}=0$.

Mutual relationship between $f_{w}$ value and the volume of volcanic products

According to the assumptions mentioned above, $f_{w}$ value for the volcanic rock might be regarded as one of useful indices for magmatism, for this value refers to the reduction rate of mass or volume relative to the initial melt. As $f_{w}$ value was derived from the inclination $S$ of the REE pattern (cf. Eq. 2), the $f_{w}$ values for the Quaternary volcanic rocks in the regions studied closely also depend on the situation of volcanoes. Figure 6 shows the relation between $f_{w}$ value and the distance of volcano from across the Quaternary volcanic front. Symbols are the same as those in Fig. 5. The right ordinate in Fig. 6 shows $f_{w}$ value on a logarithmic scale.

Then Sugimura et al. (1963) calculated the volumes of volcanic products for the Quaternary volcanoes of the East Japan volcanic belt (of which the main part is Northeast Japan) with some assumptions and demonstrated the spatial variation in volume of volcanic products in the direction normal to the island arc, i.e., from the Pacific Ocean side toward the Japan Sea side,

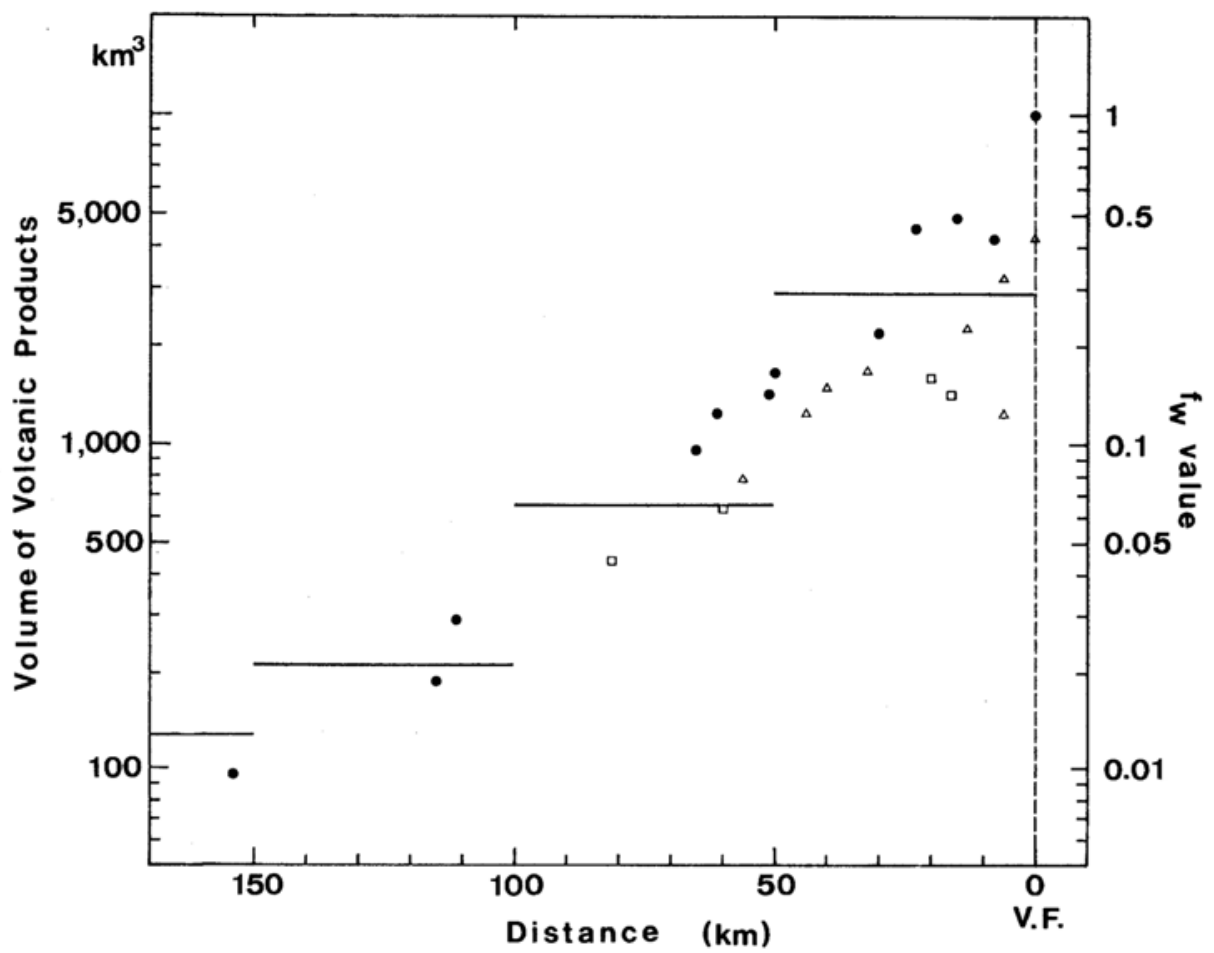

Fig. 6. Plot of $f_{w}$ value (cf. text) against the distance of volcano from the Quaternary volcanic front; symbols are the same as in Fig. 5 and bars indicate the volumes of the Quaternary volcanic products for each belt $50 \mathrm{~km}$ wide from the volcanic front in East Japan volcanic belt (SUGIMURA et al., 1963). 
employing the histogram for each belt $50 \mathrm{~km}$ wide starting from the volcanic front. Their observation has made it clear that the Quaternary volcanic products rapidly decrease in volume with the distance from the volcanic front. Figure 6 has been prepared on the basis of the data presented by Sugimura et al. (1963). The left ordinate in Fig. 6 shows logarithmically the volume of volcanic products for the Quaternary volcanoes concerned for each $50 \mathrm{~km}$ interval. It is easily seen in Fig. 6 that the rate of change of $f_{w}$ value with the distance from the volcanic front is nearly the same as that of the volume of volcanic products. Needless to say, for the volume of volcanic products, a significant factor here is its rate of change in relative magnitude. It can be emphasized that there exists close parallelism between rates of changes in $f_{w}$ value and in the volume of volcanic products.

\section{Initial "chondritic" melt}

As mentioned above, when $f_{w}$ is calculated by putting a value of $\mathrm{S}$ in Eq. (2), one can evaluate $\mathrm{C}_{O}$ for each of REE using Eq. (1). Thus the concentration level for hypothesized primary chondritic melt can be obtained from the analytical data for each volcanic rock. Figure 7 shows the result of calculation seeking for the pattern of initial melt. It is interesting that the average (open triangles) for the volcanoes situated in Northeast Japan Arc is almost the same value as the average (solid circles) for the volcanoes belonging to Kurile Arc, and that the levels of the average values are comparatively concordant with the level of the pattern for the Osore-zan basaltic andesite (broken line in Fig. 7).

Consequently, it can be inferred that the magmas of the Quaternary volcanic rocks with liquid-type REE patterns in the North eastern Japan Islands had once a stage with relatively chondritic REE abundances and developed by fractional solidification under operation of common partition coefficient function of REE as mentioned above. Difference in degree of solidification which is represented by $f_{w}$ value yields the difference in shape of REE pattern of

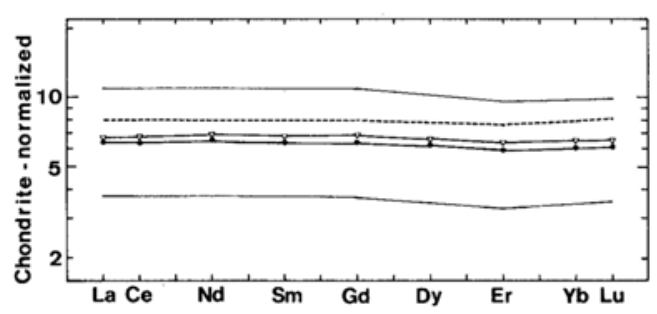

Fig. 7. Estimation of REE patterns for hypothesized initial chondritic melt of each volcanic rock; open triangle refers to the average for volcanic rocks of Northeast Japan Arc and solid circle to that for Kurile Arc. Upper fine line shows the case of the highest concentration level and lower fine line, the case of the lowest level. A broken line shows the pattern for Osore-zan volcanic rock analyzed.

the volcanic rock.

On the other hand, recent investigation of $\mathrm{Nd}$ isotope ratio for the Quaternary volcanic rocks in the same region as investigated in this study reveals that there is marked difference in $\mathrm{Nd}$ isotope ratio from volcano to volcano in the Northeast Japan Arc and that Nd isotope ratio for the volcano situated on the Pacific Ocean side shows nearly the chondritic value and the ${ }^{143} \mathrm{Nd} /{ }^{144} \mathrm{Nd}$ ratio increases toward the Japan Sea side (NoHDa and WASSERBurg, 1981). This observation may appear to contradict our inference that the volcanic rocks studied had developed from relatively chondritic melt. But this problem can be solved in line with the thought suggested by MASUdA (1979b): There are two ways responsible for the genesis of melt with relatively chondritic REE pattern. One is melting of originally chondritic materials with primitive $\mathrm{Nd}$ isotopic composition. Another is rebirth of relatively chondritic melt by a small extent of partial melting of primary solid-type materials conjugate with relatively chondritic system. The relatively chondritic melt regenerated by this process should have the high ${ }^{143} \mathrm{Nd} /{ }^{144} \mathrm{Nd}$ value in contrast with the originally chondritic melt. Here we suggest that the relatively chondritic melt which is considered the "initial" liquid for the rocks with liquid-type REE pattern is derived from two different 
sources corresponding to the difference in genetic process and that mixing takes place between them. That is, there exsist primary relatively chondritic melts with different values of $\mathrm{Nd}$ isotope ratio. This thought leads us to an inference that contribution of regenerated chondritic melt increases toward the Japan Sea side. In addition, difference in $\mathrm{Nd}$ isotope ratio for the volcanic rocks concerned seems to reflect the degree of mixing.

Solid-type REE pattern as an exceptional case

As mentioned above, the REE patterns of the Quaternary volcanic rocks in the Northeastern Japan Islands are classified mostly as liquid-type ones. Exceptionally, however, the volcanic rocks of Mashu and Kutcharo volcanoes situated in the East Hokkaido area show light REE depleted and convex REE patterns (Fig. 8). This fact was also pointed out by MASUDA, Y. and AOKI (1978). Such patterns are classified as solid-type ones and in many cases the patterns of abyssal tholeiites show similar characteristic features. It can be considered that volcanic rock with solid-type REE pattern inherits the REE pattern characteristic of aggregate of solids removed from the primary liquid-type melt under operation of linear REE partition coefficient function (MASUDA, 1966). In this connection, he demonstrated mathematically that there could be mutually conjugate, solid and liquid material systems with respect to REE abundances. If such a condition is satisfied between two systems, the REE abundance ratios between them should corre-

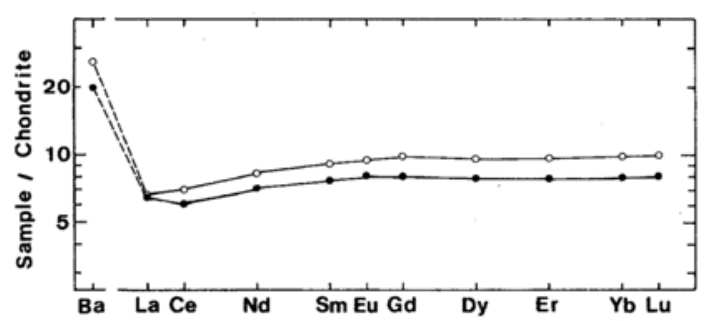

Fig. 8. Chondrite-normalized REE patterns and Ba of volcanic rocks of Mashu (solid circle) and Kutcharo (open circle) volcanoes. spond to the relevant partition coefficient function. Incidentally, it has been noticed (Fig. 9) that the REE abundance ratios of Mashu to Atosanupuri (cf. Fig. 4) appear to correspond to the rectilinear partition coefficient function with terrace-shaped character. A similar relationship is observed between Kutcharo and Atosanupuri volcanoes. It intrigues us that, geographically, Mashu and Kutcharo volcanoes are contiguous to each other and Atosanupuri volcano with liquid-type REE pattern described above is one of the sommas of Mashu volcano. It can be inferred that the volcanic rock of Mashu represents the conjugate solid phase for the Atosanupuri volcanic rock. Figure 9 shows that a set of abundance ratios in this diagram has an inflectional point at $\mathrm{Tb}$. This is concordant with the features for a majority (four out of five) of liquid-type patterns of volcanic rocks in the East Hokkaido area.

Acknowledgements-We are much indebted to Dr. Y. KATSUI of Hokkaido University, Drs. K. MIYAGI and S. NABETANI of Hirosaki University, Dr. K. AOKI of Tohoku University, Dr. S. ARAMAKI of University of Tokyo, Dr. S. NishImURA of Kyoto University, Dr. Y. MASUDA of University of Osaka Prefecture, and Dr. T. UI of Kobe University for samples studied here. Invaluable help by Dr. H. SHIMIZU of Kobe University is gratefully acknowledged.

\section{NOTE ADDED IN PROOF}

The value of D in Eq. (2) is 0.058 (MASUDA, 1979b). Further investigations about Fig. 5 are published elsewhere (FUJITANI and MASUDA, in press).

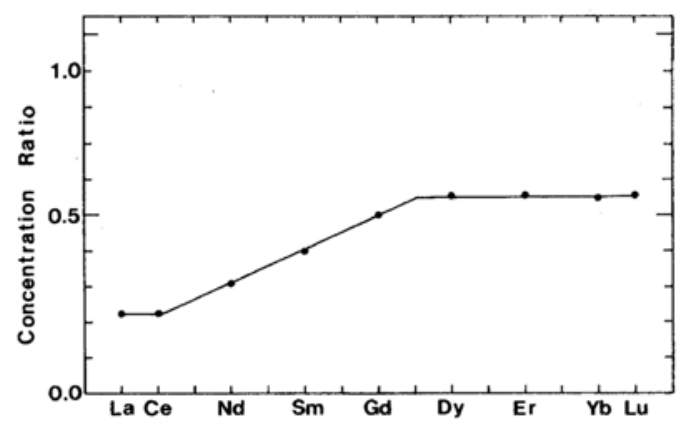

Fig. 9. Plot of concentration ratios of REE abundances of volcanic rock of Mashu volcano to Atosanupuri, against the atomic number. 


\section{REFERENCES}

FUJIMAKI, H. and KuRASAWA, H. (1980) Lateral variation of REE pattern of basaltic magma across the Japan arc. J. Japan Assocn. Min. Petr. Econ. Geol. 75, 313-322.

FUJTTANI and MASUDA (in press) An attempt to locate a new front with the horizontal REE pattern, for Northeast Japan Island Arcs. Review of Marine technical college.

HARTHERTON, T. and DICKINSON, W. R. (1969) The relationship between andesitic volcanism and seismicity in Indonesia, the Lesser Antilles, and other island arcs. J. Geophys. Res. 74, 5301-5310.

HAWKESWORTH, C. J., O'NION, R. K., PANKHURST, R. J., HAMILTON, P. J. and EVENSEN, N. M. (1977) A geochemical study of island-arc and back-arc tholeiites from the Scotia Sea. Earth Planet. Sci. Lett. 36, 253-262.

JAKES, P. and WHITE, A. J. R. (1969) Structure of the Melanesian arcs and correlation with distribution of magma types. Tectonophys. 8, 223-236.

JAKES, P. and GILL, J. (1970) Rare earth elements and island arc thoeliite series. Earth Planet. Sci. Lett. 9, 17-28.

KATSUI, Y. (1961) Petrochemistry of the Quaternary volcanic rocks of Hokkaido and surrounding areas. J. Fac. Sci., Hokkaido Univ., Ser. 4, 11, 1-58.

KAY, R. W. and HUBBARD, N. J. (1978) Trace elements in ocean ridge basalts. Earth Planet. Sci. Lett. 38, 95-116.

KuNO, H. (1959) Origin of Cenozoic petrographic provinces of Japan and surrounding areas. Bull. Volcanol., Ser. 2, 20, 37-76.

KUNO, H. (1966) Lateral variation of basalt magma type across continental margins and island arcs. Bull. Volcanol. 29, 195-222.

LE PICHON, X. (1968) Sea-floor spreading and continental drift. J. Geophys. Res. 73, 3611-3697.

MASUDA, A. (1966) Lanthanides in basalts of Japan with three distinct types. Geochem. J. 1, 11-26.

MASUDA, A. (1979a) Effects of linear bulk partition coefficient functions of REE: liquid-type and solidtype as a basic framework. J. Earth. Sci. Nagoya Univ. 26/27, 95-112.

MASUDA, A. (1979b) Remarkable aspects of REE geochemistry, with particular reference to bulk partition control effect of integral natures. Recent Progress of Natural Sciences in Japan 4, 1-9.

Masuda, A., NaKamura, N. and TANaKa, T. (1973) Fine structures of mutually normalized rare-earth patterns of chondrites. Geochim. Cosmochim. Acta 37, 239-248.

Masuda, A., Shimizu, H. and Inenaga, N. (1977)
Search for chemical effect on partitioning of rareearth elements in the crystallization process of basaltic systems at $20 \mathrm{~kb}$, with some applications. Geochem. J. 11, 21-32.

MASUDA, Y. and AOKI, K. (1978) Two types of island arc tholeiite in Japan. Earth Planet. Sci. Lett. 39, 298-302.

Masuda, Y., Nishimura, S., IKedA, T. and Katsui, Y. (1975) Rareearth and trace elements in the Quaternary volcanic rocks of Hokkaido, Japan. Chem. Geol. 15, 251-271.

NOHDA, S. and WASSERBURG, G. J. (1981) Nd and $\mathrm{Sr}$ isotopic study of volcanic rocks from Japan. Earth Planet. Sci. Lett. 52, 264-276.

PhilpotTS, J. A., MARTIN, W. and SCHNETZleR, C. C. (1971) Geochemical aspects of some Japanese lavas. Earth Planet. Sci. Lett. 9, 17-28.

SAKUYAMA, M. (1979) Lateral variations of $\mathrm{H}_{2} \mathrm{O}$ contents in Quaternary magmas of Northeastern Japan. Earth Planet. Sci. Lett. 43, 103-111.

SCHILliNG, J. -G. (1971) Sea-floor evolution: rareearth evidence. Phil. Trans. Roy. Sco. London, Ser. A, 268, 663-706.

SHIMIZU, H. (1980) Experimental study on rareearth element partitioning in minerals formed at 20 and $30 \mathrm{~kb}$ for basaltic systems. Geochem. J. 14, 185-202.

ShimizU, H., Masuda, A. and TANAKa, T. (1979) Two major groups of chondritic REE abundances suites: variable octad effect on heavy REE. Mem. Natl. Inst. Polar Res. Issue 15, 171-176.

SHIMOKAWA, T. and MASUDA, A. (1972) Rare-earths in Icelandic neovolcanic rocks. Contrib. Mineral. Petrol. 37, 39-46.

SUGIMURA, A. (1960) Zonal arrangement of some geophysical and petrological features in Japan and its environs. J. Fac. Sci., Univ. Tokyo, Sect. 2, 12, 133-153.

SugimurA, A. (1968) Spatial relations of basaltic magmas in island arcs. In: Basalt: the Poldervaart Treatise on Rocks of Basaltic Composition (H. H. HESS and A. POLDERVAART, ed.) 2, 537-571, Interscience, New York.

Sugimura, A. and UYEDA, S. (1973) Island Arcs, Japan and Its Environs, Elsevier, Amsterdam.

Sugimura, A., Matsuda, T., Chinzei, K. and NAKAMURA, K. (1963) Quantitative distribution of late Cenozoic volcanic materials in Japan. Bull. Volcanol., Ser. 2, 26, 126-140.

TANAKa, T. and Nishizawa, O. (1975) Partitioning of REE, Ba and $\mathrm{Sr}$ between crystal and liquid phases for a natural silicate system at $20 \mathrm{~kb}$ pressure. Geochem. J. 9, 161-166.

TAYLOR, S. R. and WHITE, A. J. R. (1965) Geo- 
chemistry of andesites and the growth of continents. Nature 208, 271-273.

TOMITA, T. (1937) On the chemical composition of the Cenozoic alkaline suite of the Circum-Japan Sea region. J. Shanghai Sci. Inst., Sect. II, 1, 227-306.

UI, T. and ARAMAKI, S. (1978) Relationship between chemical composition of Japanese island arc volcanic rocks and gravimetric data. Tectonophys. 45, 249-259.

YAJima, T., HiguCHI, H. and NAGASAWA, H. (1972) Variation of rare earth concentrations in pigeonitic and hypersthenic rock series from Izu-Hakone region, Japan. Contrib. Mineral. Petrol. 35, 235-244. 